\title{
Research on Traditional Village Protection Based on Value Evaluation
}

\author{
Chen Lipeng*, Chao Yaoming \\ Urban Planning, Southeast University, Nanjing, China
}

\section{Email address:}

1711848523@.com (Chen Lipeng),ym.chao@163.com (Chan Yaoming)

${ }^{*}$ Corresponding author

\section{To cite this article:}

Chen Lipeng, Chao Yaoming. Research on Traditional Village Protection Based on Value Evaluation. Science Discovery. Vol. 7, No. 5, 2019, pp. 291-298. doi: 10.11648/j.sd.20190705.16

Received: August 17,2019; Accepted: October 16, 2019; Published: October 23, 2019

\begin{abstract}
The traditional village inherits a long history and culture, is an important carrier of harmonious symbiosis between the countryside and the natural environment, and is the essence of rural civilization and the crystallization of culture and art. Traditional villages play a very important role in displaying local culture, protecting outstanding historical buildings and local material resources. In the 21 st century, traditional Chinese villages face many difficulties such as the accelerated speed of disappearance, the lack of traditional culture, the weak development of the protection of material and non-material elements. Taking Cangkou Village of Nanjing as an example, the material and cultural elements within the village are evaluated for their value from the two levels of value characteristics and strategic measures. According to the results of the value assessment, all material cultural resources points are classified into four levels,and different targeted protection levels of material and cultural elements is carried out; the inheritance of intangible culture and protection also needs to be strengthened. To achieve the protection of traditional villages, on the basis of government policy guarantees, targeted innovations in protection measures are also needed. In the past, the research on the protection of traditional villages was mainly qualitative. The research in this paper focuses on the combination of quantitative and qualitative, and has certain reference significance for the protection research of traditional villages.
\end{abstract}

Keywords: Value Evaluation, Traditonal Village, Protection, Cangkou Village

\section{基于价值评估的传统村落保护研究}

\author{
陈立鹏"，巢耀明 \\ 东南大学建筑学院, 南京, 中国
}

邮箱

1711848523@qq.com（陈立鹏）,ym.chao@163.com（巢耀明）

摘要：传统村落传承悠久的历史文化技艺, 是乡村与自然环境和谐共生的重要载体,是乡村文明的精髓、文化艺术的结 晶。传统村落在展示地方特色文化、保护优秀历史建筑和地方特色物质资源方面发挥了非常重要的作用。进入21世纪, 中国传统村落面临消失速度加快、传统文化后继无人、物质和非物质要素保护发展乏力等诸多困境。以南京市仓口村 为例, 针对村庄范围内的物质文化要素, 从价值特色以及策略措施两个层次对其进行价值评估, 根据价值评估结果, 将所有的物质文化资源点进行分级，共分四个等级，对不同等级的物质文化要素进行有针对性的保护; 对非物质文化 的传承和保护也需要加强。要实现传统村落的保护, 在政府政策保障的基础上, 也需要对保护措施进行有针对性的创 新。以往针对传统村落的保护研究以定性为主, 本研究注重对于物质文化资源进行定量与定性相结合的分析, 对于传 统村落的保护研究具有一定的借鉴意义。 
关键词：价值评估, 传统村落, 保护, 仓口村

\section{1. 引言}

近年国家提出“美丽中国建设”的政策，江苏省政府专 门制定了《江苏省传统村落保护办法》。加强对于传统村 落物质与非物质要素的保护与传承, 改善提升传统村落的 人居环境, 延续传统村落的空间布局模式, 逐渐成为传统 村落保护的主要内容。在这种背景下, 本文以南京市仓口 村为例, 从价值特色以及保护策略措施两个层次对村庄范 围内的历史文化资源进行价值评估，进而针对不同等级的 资源点进行有针对性的保护, 拓展传统村落保护与发展的 内容, 研究具有一定的现实意义。近年来, 国内相关专业 的学者对于传统村落开展了大量的研究。从研究内容来 看, 各学科针对自身学科优势对于传统村落的保护与发展 都提出了宝贵的建议, 如城乡规划学侧重分析国家宏观政 策背景对于传统村落保护的影响, 比乡村振兴以及美丽中 国建设 $[1,2]$, 建筑学侧重对于建筑单体以及传统居住空 间的研究 [3], 社会学侧重于对村落公共空间和多视角的传 统文化进行分析[4]。从研究方法来看, 之前的研究偏重定 性分析, 近几年随着GIS技术的应用, 逐渐转变为定性与 定量分析相结合, 尤其是利用GIS-RS技术对传统村落进行 微观研究 [5]。本文即运用定量与定性相结合的分析方法, 对于研究范围内的物质文化资源点进行量化价值评定, 进 而针对不同等级的文化资源点提出不同的保护措施。

\section{2. 传统村落研究概述}

中国传统村落研究大致经历了 3 个阶段：第一阶段, 缓慢起步阶段（20世纪90年代至2006年），由于当时国家 重心在城镇建设上, 农村发展还未得到太大关注, 传统村 落也未受到太多关注; 第二阶段, 成长壮大阶段（2007 至2011年），国家政策的引导对于传统村落的保护和发展 研究起到了促进作用; 第三阶段, 迅猛发展阶段 (2012 年至2017年）, 2012年之后传统村落的保护发展工作上升 为国家发展战略, 传统村落名单的推出进一步推动了传统 村落的保护与发展。

\section{1. 传统村落空间形态研究}

地域空间环境是传统村落的重要组成部分, 其中建筑 的直观表达体现为空间结构与形态的演变[6]。在传统村落 研究中, 空间形态与空间布局一直是学者们的研究热点。 研究范围从宏观的全国区域到微观视角的个体村落均有 研究。研究内容涉及到不同地域尺度的空间分布规律 [7] 及其影响因素 $[8]$ 、以及研究在特定政策背景下地域空间的 重构[9]等。

“地方性”是对传统村落空间文化价值进行深入挖掘 的关键 [10], 翟洲燕等人从物质和非物质两大层面挖掘传 统村落空间的文化价值[11]。村落景观和文化遗产是凸显 传统村落文化价值的直观表达, 林琳等人从文化景观基因 视角对传统村落的格局、激励和建筑元素进行了研究 [12]。
文化遗产是传统村落生存的精神根基, 是当地独一无二的 价值遗产, 对文化遗产的个案研究是对原真性的最大保护 [13]。

\section{2. 传统村落社会文化研究}

传统村落社会文化包括物质和非物质两部分, 物质文 化是指村落传统建筑、构筑物、器物等随着历史推移所承 载的文化含义; 非物质社会文化涵盖村落的民俗文化和社 会活动, 主要指在村落发展过程中形成的民风民俗等。翟 洲燕对地方文化景观做过多方面的研究 [14], 杨立国等人 对传统村落文化传承度进行指标构建和综合评价[15]。随 着针对传统村落研究的不断深入, 传统村落生态建设问题 开始凸显。麻勇恒提议设立传统农耕保护区, 走民族地区 “乡市化”发展模式[16]。在现如今文化创意产业正如火如 茶发展的大背景下, 将文化创意产业和传统村落旅游发展 相融合是当下传统村落保护和发展的新趋势[17]。旅游开 发与文化保护二者是相辅相成的关系, 适度进行旅游开发 对民族村落文化生态平衡也是一种促进 [18]。

\section{3. 传统村落生态环境研究}

传统村落生态环境建设是村落内景观构建的基础 [19]。李艳华以榆次后沟村为例, 阐述文化生态环境下的 人文精神与生活方式对新农村建设中生态环境设计的指 导性意义[20]。李慧敏对国家历史文化名村的历史空间形 态进行分析, 探索了古代人居环境构造原型以及如何对其 村落空间结构进行营造[21]。刘倩颖侧重探讨自然环境生 态对村落的整体布局和发展形态的影响[22]。李伯华等人 将传统村落人居环境作为一个生态系统, 研究了传统村落 人居环境的演变特征和驱动机制[23]。

\section{3. 仓口村现状研究}

仓口村位于南京市溧水区洪蓝街道办事处塘西行政 村南部, 于2016年被评为江苏省传统古村落。仓口村历史 悠久, 村庄三面临水, 在其村域内拥有众多明清建筑, 5 条老街巷纵横交错, 仍保存着古村格局。

\section{1. 村落历史沿革}

春秋: 吴王槛闾伐楚时, 伍子胥建议开挖一条输送粮 草的运河, 属于“中江”的一部分, 名叫荆溪, 荆溪源出高 淳县的固城湖, 东通太湖, 西入长江, 仓口村就在荆溪附 近。

明代: 明代之前, 仓口村又称梅梁村, 由于连着石臼 湖, 村子三面临水, 所以也被称为梅梁渡。

近代: 随着漕运日益衰落, 仓口的古渡要塞地位逐渐 失去。但村庄格局并未发生太多变化, 至今保留着一定量 的传统民居和祠堂等建筑及漕运码头, 加之村庄地理位置 独特, 三面临水、圩区特色明显。 


\section{2. 村落建筑风貌}

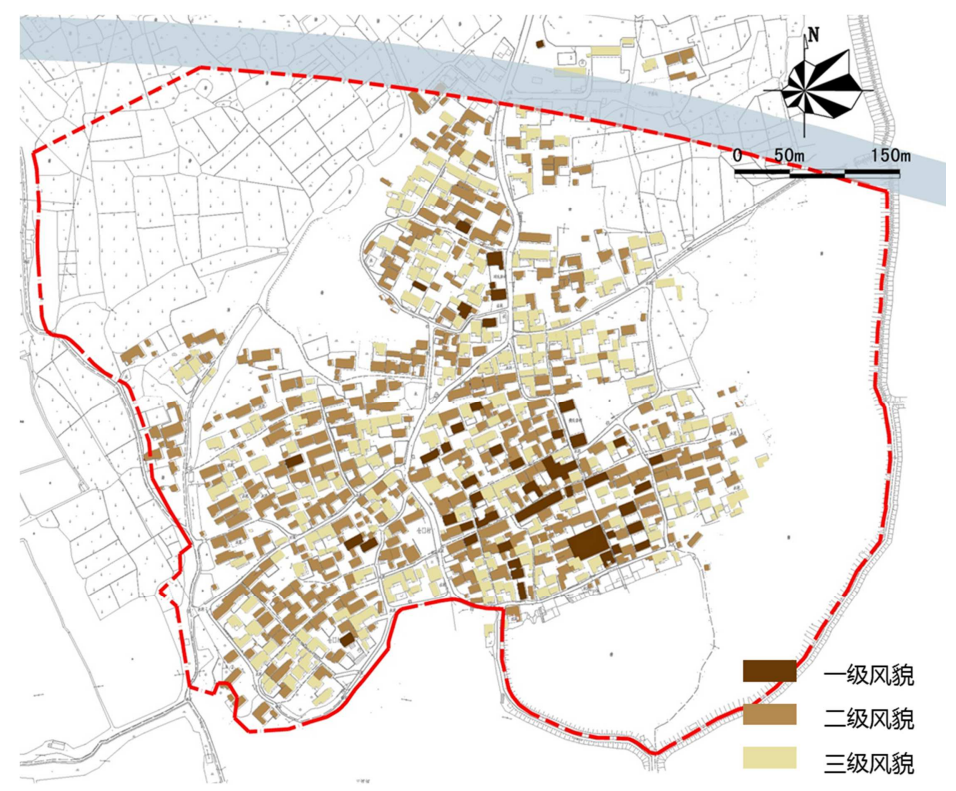

图1 村落建筑风貌现状图。

按照建筑风貌主要分为三类:

一级风貌: 传统风貌建筑, 具有典型地方特色, 这些 建筑形成古村落传统风貌的重要因素。

二级风貌：与传统民居风貌相协调的建筑，指采用传 统建筑做法, 风貌部分损坏的传统建筑或是延续原有空间 肌理的近现代质量一般的建筑。

三级风貌：与传统民居风貌较不协调的建筑。指质量 差的建筑, 或采用了瓷砖、红砖等装饰材料。它们从体量、 外观和色彩上对风貌区的整体风貌有较大影响。

\section{3. 村落现状资源点分布}

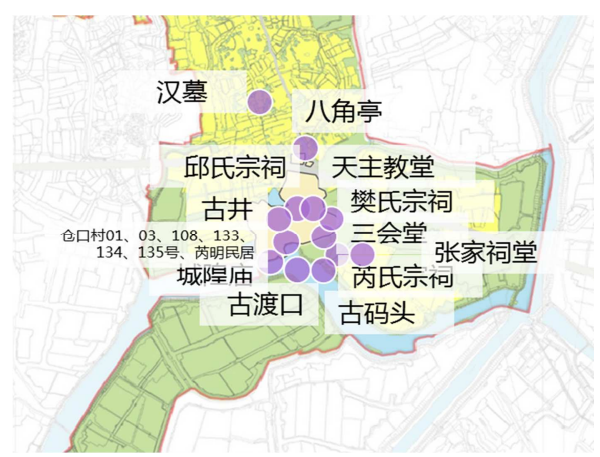

图2 仓口村落现状物质资源点分布图。

现状村庄内保留了芮氏祠堂、栎氏祠堂、邱氏祠堂、 城隍庙、古渡口遗址、古码头、三会堂、八角亭以及列入
洪蓝街道特色资源名录的7处传统民居。其中，芮氏祠堂 为南京市市级文保单位。

\section{4. 历史文化遗产价值评估}

建立因子评估指标体系, 对于村落范围内的具有保护 价值的历史文化资源点进行价值评估, 将这些资源点进行 等级划分, 并针对不同等级的资源点提出保护措施。

\section{1. 评价指标体系构建}

引入“分层设定，两级指标，各赋权重，四阶分值”的 基本模式, 建构具有特色的评估指标体系, 该指标体系引 用了吴晓、王承慧等人在编制《大运河遗产保护规划》时 提出的水利工程设施的评估指标体系[24]。在评估指标和 因子设定上彰显“古村相关性”导向。根据规划地区的历 史、经济、社会等特点, 价值特色评估层次选取七个一级 因子：历史价值因子、社会价值因子、艺术价值因子、情 感价值因子、延续性因子、真实性因子、完整性因子。措 施策略评估层次选取四个一级因子：历史使用状况因子、 现代使用状况因子、历史管理状况因子、现代管理状况因 子，每个一级因子下设二到七个二级因子。

部分因子在现场无法即时做出评定, 如历史价值、社会 价值、真实性. 完整性和历史管理状况等, 结合文献查阅、 访谈、推导等方法, 以“古村相关性”为指向, 通过历史视野 下资料信息的考据梳理与演化脉络的解析做出综合判断。

表1 价值评估内容。

\begin{tabular}{llll}
\hline 层次划分 & 各层次的指标构成 & 评估目标 & 具体职能 \\
\hline $\begin{array}{l}\text { 层次一: 价值特色评估 (核心层 } \\
\text { 次) }\end{array}$ & 综合价值, 保存现状等 & 建立准入门槛 & 为各类遗存的评估分级和遴选提供依据, 决定可 \\
$\begin{array}{lll}\text { 层次 } 2: \text { 措施策略评估 (外延层 } \\
\text { 次) }\end{array}$ & 展示状况, 利用状况, 管理状况等 & 提升保护标准 & $\begin{array}{l}\text { 为遗存的科学管控和合理整治提供依据, 是层次 } \\
1 \text { 的延伸; 与应对 }\end{array}$ \\
\hline
\end{tabular}




\section{2. 遗产价值评估}

对于仓口村落内的所有物质物质资源点进行价值量 化。通过因子的叠加计算, 形成价值特色评估结果, 将相 关遗存划分为不同等级: 价值特色评估大于 80 分, 为一级 保护类遗存; 价值特色评估介于 70 - 80 分, 为二级保护类 遗存; 价值特色评估介于 60-70分, 为三级保护类遗存, 价值特色评估低于 60 分, 为非保护类遗存。
根据等级的不同, 确定不同建筑保护与整治措施, 三 类等级分别对应文物建筑、保护类建筑和改善类建筑, 并 且确定相应的指定保护、登录保护和规划控制三类保护措 施。仓口村规划范围内共有 46 处物质文化遗存, 分类包括 祠堂、庙宇、传统民居、构筑物（含古井、古渡口等）四 大类。其中一级保护类遗存 1 个, 为市级文保单位一一苪 氏宗祠 (1号); 二级保护类遗存 16 个(本应为 19 处, 仓口 村民居02、梅梁渡以及仓口村陈氏老宅匿失), 三级保护 类遗存 29 个。

表2 价值量化评定表。

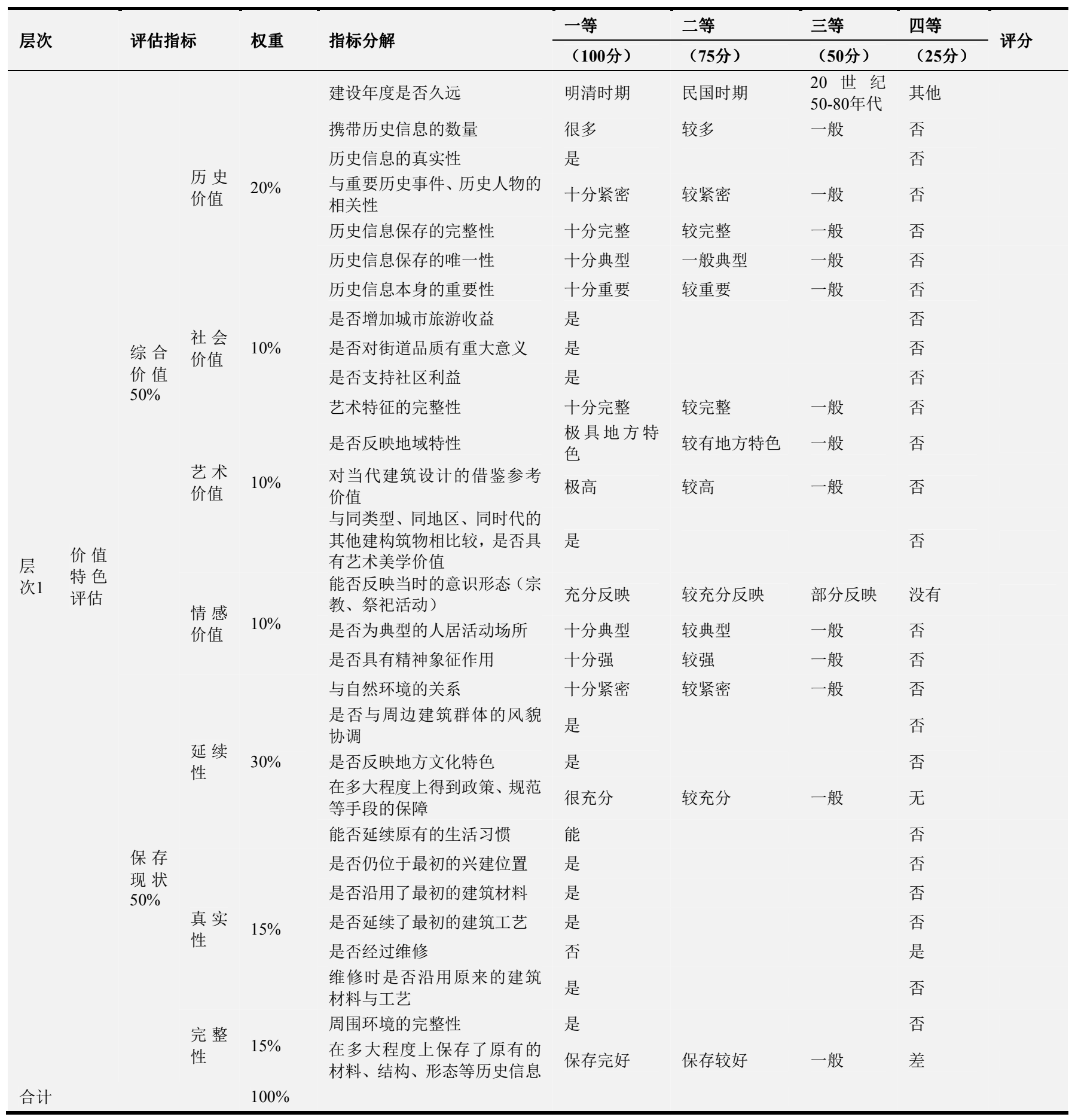




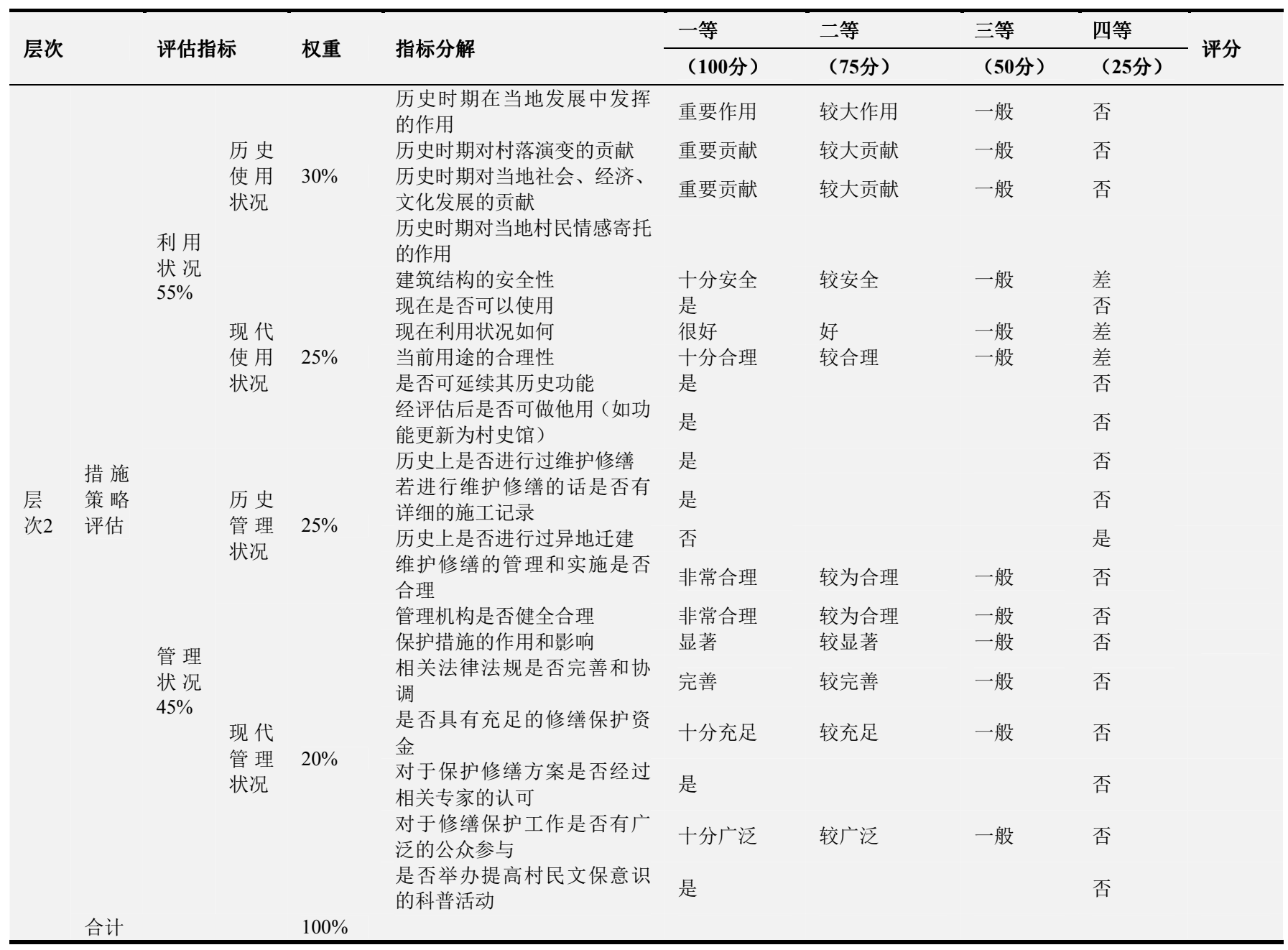

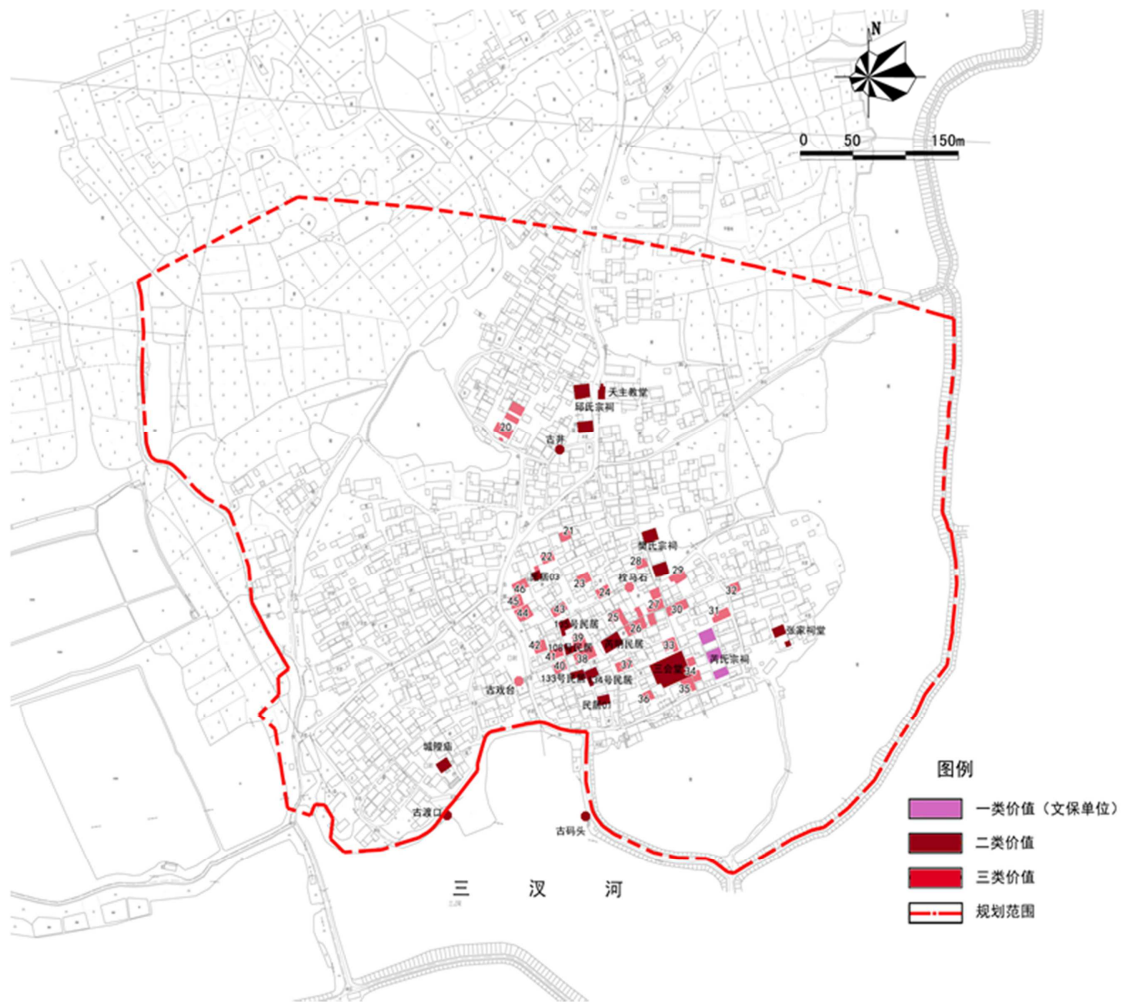

图3 仓口村落不同等级遗存图。 


\section{5. 历史文化遗存保护与利用}

\section{1. 仓口村落保护框架}

划定核心保护范围, 西至仓口路以西、南至沿河道路、 北至邱氏祠堂以北、东至森氏宗祠, 包含所有明清历史遗 存建筑, 面积为 5.36 公顷。

划分为重要保护点、核心保护区、建设控制地带、风 貌协调区四个层次。

重要保护点的保护: 重要保护点主要包括芮氏宗祠、 樊氏宗祠、邱氏宗祠、三会堂和部分明清民居建筑等。这 些建筑质量好, 历史价值高, 要进行最严格的保护, 完整 地体现原有的历史信息，不允许对其作任何大的改动。

核心保护范围的保护：核心保护范围西至仓口路以 西、南至沿河道路、北至邱氏祠堂以北、东至张家祠堂, 包含所有明清历史遗存建筑, 占地为5.36公顷。在保护整
治中, 要求“空间结构完整, 传统风貌完好, 视觉景观连 续”。历史建筑的整治改造应统一规划, 统一设计, 但具 体的修复建议采用循序渐进的方式。

建设控制地带的保护: 建设控制地带指核心保护区以 外一定的距离内, 为了协调仓口古村落人工环境的整体形 态和风貌, 结合街道、河流等明显的地理界限而设置的区 域。建设控制地带9.72公顷, 范围东至林塘、南至三汉河、 西至现状村庄自然边界, 北至341省道。

风貌协调区：风貌协调区指在建设控制区以外、村庄 规划范围内的建 (构) 筑、自然水体和绿化等, 面积约 15.06 公顷。在该区域内, 严禁侵占水体和基本农田, 严禁发展 有污染型的工业, 逐力恢复并改善仓口村外部生态环境, 保护村域内的农田耕地, 并可做适当的旅游性开发。风貌 协调区内要防止建设过洋、过大、过于现代的建筑。

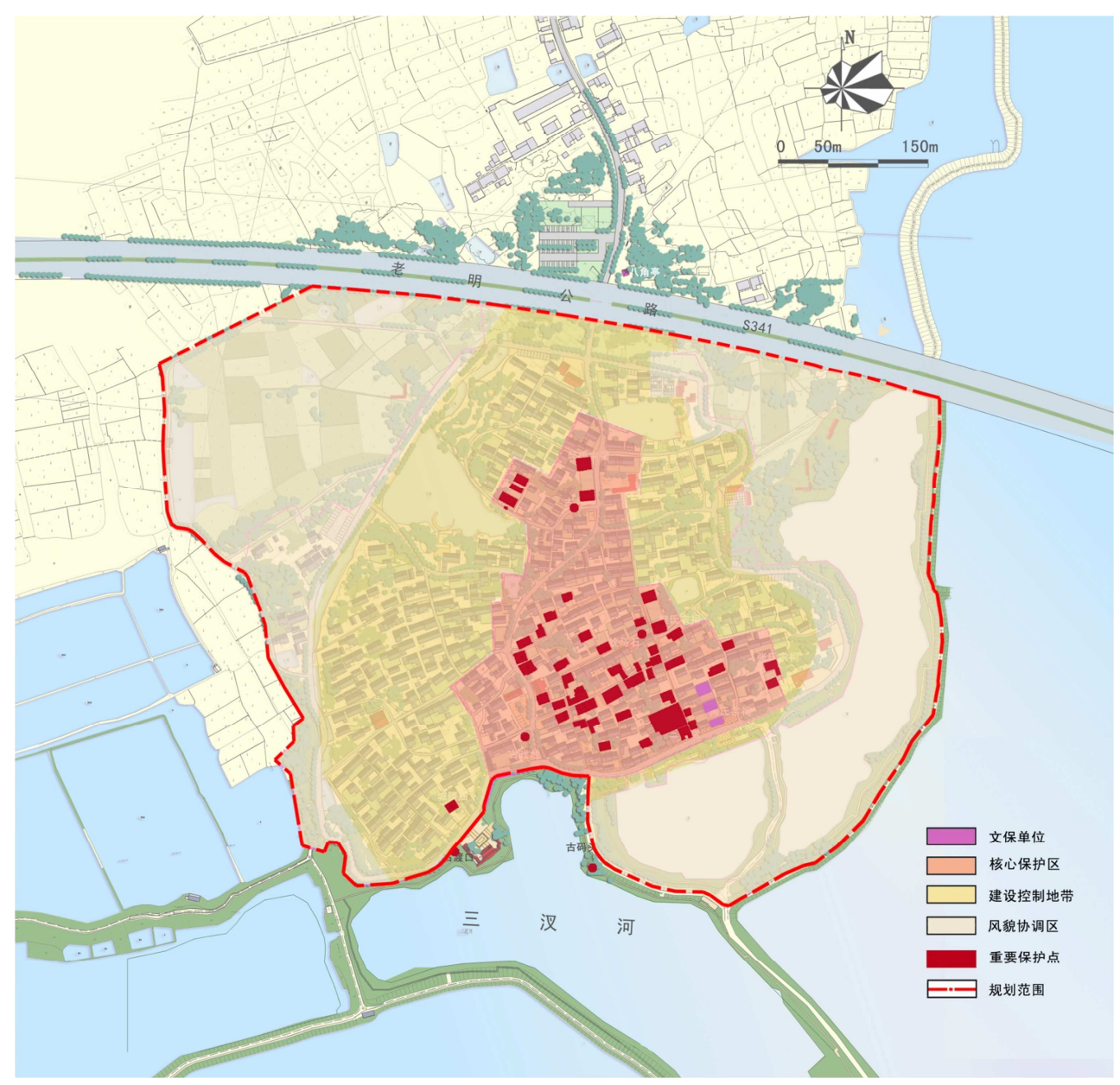

图4 仓口村落保护范围划定图。

\section{2. 建构筑物保护与整治}

为实现仓口古村落的传统风貌协调统一, 古村落的其 他建筑必须与传统建筑风貌相协调, 不协调者要进行必要 的整治。本规划将仓口古村落建筑的保护和整治模式分为 五类，即文物类建筑、保护类建筑、改善类建筑、保留类 建筑、拆除类建筑。
文物类建筑: 仓口古村落中的这类建 (构) 筑主要为 市级文物保护单位的芮氏宗祠, 其历史价值评定为一级。 对这类建（构）筑的保护和整治, 必须按照《中华人民共 和国文物保护法》严格保护，不折不扣地坚持“维护文物 原状”的原则和“保护为主，抢救第一，合理利用，加强管 理”的方针, 进行逐步的修缮, 并最大限度地使用原材料、 
原工艺、原造型、原色调、原纹理, 如实维持历史原貌, 不得损毁、改建、添建或者拆除。

保护类建筑：仓口古村落中的这类建（构）筑为邱氏 宗祠、焚氏宗祠、张家祠堂、天主教堂、城隍庙、三会堂、 古渡口、古码头、7处列入洪蓝街道具有法定保护的物质 文化资源名录的传统民居。不允许改变这类建筑外立面原 有的特征和基本材料, 必须按照原有特征、使用相同材料 进行修复, 可见部分均应使用旧木料、旧石料、旧砖瓦, 严格按照其原始状态, 做到修旧如故, 做好详尽的修嗱纪 录。

改善类建筑: 仓口古村的这类建筑物主要为传统风貌 保护区内的传统民居。对于建筑立面经过了改动和采用现 代的材料和手法的建筑, 要对其立面进行整治, 力求恢复 其传统风貌, 整治中要采用传统的手法和材料, 力求做到 原汁原味。对于主体结构大部分已损坏的建筑, 根据其历 史价值、重要程度、损害程度等因素, 可采用遗址保护或 原样修复。

保留类建筑: 仓口村落中立面或形态不符合传统风貌 的建筑要逐步进行整治, 使其与传统风貌相协调, 减少其 和整体风貌的冲突。仓口古村这类建筑多为 $1-2$ 层砖混结 构, 部分建筑材料采用旧时青砖, 质量较好, 如果与周围 环境冲突不大，可维持现状。

拆除类建筑：保护区内的建筑，如视觉影响严重，不 易通过整治的方式而达到和传统风貌协调的目的, 且价值 不大, 要选择拆除的方式。由于种种原因在短期内无法拆 除的, 应暂时维持现状, 等条件成熟时拆除。逐步拆除重 要传统院落内临时搭建的厨房、则所等建筑。村内的违章 建筑, 可以结合古村落的整治, 逐步拆除。

\section{6. 结语}

传统村落保护与历史文化名城相比较, 保护力度不 强, 尚未形成统一的规范性文件。传统村落是前人留下来 的宝贵财富, 我们有义务和责任保护好传统村落。传统村 落的开发利用应以保护为前提。传统村落的保护工作任重 道远，不同地域的传统村落保护应因地制宜，努力探索符 合当地实际的传统村落保护与利用之路。

\section{致谢}

本文受国家自然科学基金资助（项目批准号: 51678131、51678130）。

\section{参考文献}

[1] 王金敖.乡村振兴视阈下的台州传统村落可持续发展路径 探讨 [J].浙江农业科学, 2019，60 (5): 840-843，847。

[2] 谢青玉. “美丽乡村”视阈下河南省传统村落保护与发展的生 态适应性研究 [J] . 甘肃农业, 2019, (04): 47-50。
[3] 邢晶晶. 基于延续性视角的传统村落保护与发展研究 [D] . 长沙: 湖南师范大学, 2015。

[4] 乔小河. 时间与空间中的西藏农村民居 [D] . 北京：中央 民族大学，2012。

[5] 董艳平, 刘树鹏. 基于 GIS的山西省传统村落空间分布特 征研究 $[\mathrm{J}]$. 太原理工大学学报, 2018, 49 (5): 771-776。

[6] 卢松, 张小军, 张业臣. 徽州传统村落的时空分布及其影 响因素 $[\mathrm{J}]$ 。地理科学, 2018, 38 (10) : 1690-1698。

[7] 刘大均, 胡静, 陈君子, 等. 中国传统村落的空间分布格 局研究 $[\mathrm{J}]$. 中国人口.资源与环境, 2014，24 (4)：157 -162 .

[8] 李伯华, 周釒金, 刘沛林, 等. 城镇化进程中张谷英村功能 转型与空间重构 $[\mathrm{J}]$. 地理科学, 2018, 38 (8) : 1310-1318。

[9] 王景新, 支晓娟. 中国乡村振兴及其地域空间重构: 特色小 镇与美丽乡村同建振兴乡村的案例、经验及未来 $[\mathrm{J}]$. 南 京农业大学学报: 社会科学版, 2018, 18 (2) : 17-26; 157 -158 。

[10] 范建红, 莫悠. 基于田园综合体的广州龙洞村景观保护规 划 $[\mathrm{J}]$. 工业建筑，2019，49 (1) : 99; 189-193。

[11] 翟洲燕, 李同昇, 常芳, 等. 传统村落文化对城乡一体化 的统筹性响应机理 $[\mathrm{J}]$. 人文地理, 2017, 32(4) : 30-36。

[12] 林琳, 田嘉铄, 钟志平, 等. 文化景观基因视角下传统村 落保护与发展: 以黔东北土家族村落为例 $[\mathrm{J}]$. 热带地理, 2018，38(3) : 413-423。

[13] 秦红增, 曹晗. 新文化空间的建构与前瞻: 从耕读传家到乡 村新习 $[\mathrm{J}]$. 广西民族大学学报: 哲学社会科学版, 2016, $38(6): 8-15$ 。

[14] 翟洲燕, 王兴中. 基于社区体系结构的社区资源可获性评 价原理研究 $[\mathrm{J}]$. 世界地理研究, 2012, 21 (2) : 144-50。

[15] 杨立国, 刘沛林. 传统村落文化传承度评价体系及实证研 究: 以湖南省首批中国传统村落为例 $[\mathrm{J}]$. 经济地理, 2017, 37 (12) :203-210。

[16] 麻勇恒. 传统村落保护面临的困境与出路 [J]．原生态民 族文化学刊, 2017, 9 (2) : 89-94。

[17] 孔翔, 卓方勇, 苗长松. 旅游业发展状况对古村落文化保 护的影响：基于对宏村、呈坎、许村居民的调研 [ $\mathrm{J}]$. 热 带地理，2016，36 (2): 216-224。

[18] 黄震方, 黄叡. 城镇化与旅游发展背景下的乡村文化研究: 学术争鸣与研究方向 [J] . 地理研究, 2018, 37 (2): 233 -249 。

[19] 李伯华, 曾荣倩, 刘沛林, 等.基于CAS 理论的传统村落 人居环境演化研究: 以张谷英村为例 $[\mathrm{J}]$. 地理研究, 2018 , 37 (10): 1982-1996。

[20] 李艳华. 村落文化生态环境的解析及对新农村生态环境设 计的启示：以榆次地区后沟村为例 [J].中国美术, 2014(4) : $122-124$ 。 
[21］李慧敏, 王树声. 古村落人居环境构建原型及文化景观环 境营造: 以国家历史文化名村夏门为例 $[\mathrm{J}]$. 西北大学学 报: 自然科学版, 2012, 42 (5): 849-852。

[22] 刘倩颖.自然条件对村落形态和布局的影响 [J]. 农业科 技与信息 (现代园林), 2010 (4): 30-32。
[23] 李伯华, 刘沛林, 窦银娣, 等. 中国传统村落人居环境转 型发展及其研究进展 $[\mathrm{J}]$. 地理研究, 2017，36 (10): 1886 -1900 。

[24] 吴晓, 王承慧, 王艳红. 大运河遗产保护规划 (市一级) 的总 体思路探析 $[J]$. 城市规划, 2010，34 (09): 49-56。 